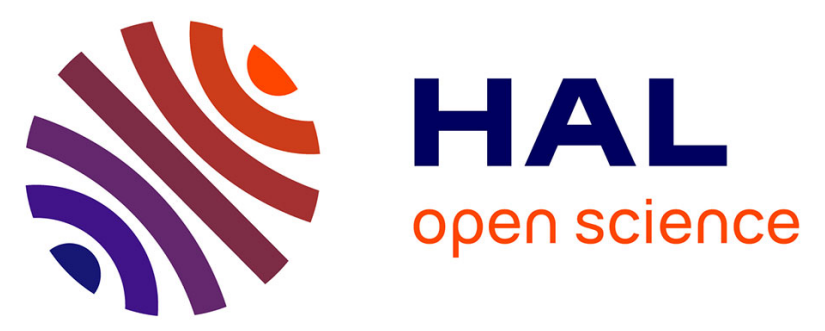

\title{
Viscoelastic modeling and quantitative experimental characterization of normal and osteoarthritic human articular cartilage using indentation
}

Fabrice Richard, Mylène Villars, Sébastien Thibaud

\section{- To cite this version:}

Fabrice Richard, Mylène Villars, Sébastien Thibaud. Viscoelastic modeling and quantitative experimental characterization of normal and osteoarthritic human articular cartilage using indentation. Journal of the mechanical behavior of biomedical materials, 2013, 24, pp.41 - 52 . 10.1016/j.jmbbm.2013.04.012 . hal-02300238

\section{HAL Id: hal-02300238 \\ https://hal.science/hal-02300238}

Submitted on 29 Sep 2019

HAL is a multi-disciplinary open access archive for the deposit and dissemination of scientific research documents, whether they are published or not. The documents may come from teaching and research institutions in France or abroad, or from public or private research centers.
L'archive ouverte pluridisciplinaire HAL, est destinée au dépôt et à la diffusion de documents scientifiques de niveau recherche, publiés ou non, émanant des établissements d'enseignement et de recherche français ou étrangers, des laboratoires publics ou privés. 
Viscoelastic modeling and quantitative experimental characterization of normal and osteoarthritic human articular cartilage using indentation

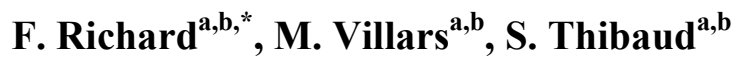

${ }^{a}$ Université de Franche-Comté, 25000 Besançon, France

${ }^{b}$ FEMTO-ST Institute, Department of Applied Mechanics, UMR CNRS 6174, 24 rue de l'Epitaphe, 25000 Besançon, France.

"Corresponding author:

Tel.: +33 (0)3 816667 10; fax: 33(0)3 816667 00; E-mail: fabrice.richard@univ-fcomte.fr

\section{Keywords:}

indentation, viscoelastic, damage, human cartilage, osteoarthritis, identifiability, inverse method 


\begin{abstract}
The viscoelastic behavior of articular cartilage changes with progression of osteoarthritis. The objective of this study is to quantify this progression and to propose a viscoelastic model of articular cartilage taking into account the degree of osteoarthritis that which be easily used in predictive numerical simulations of the hip joint behavior.

To quantify the effects of osteoarthritis (OA) on the viscoelastic behavior of human articular cartilage, samples were obtained from the hip arthroplasty due to femoral neck fracture (normal cartilage) or advanced coxarthrosis (OA cartilage). Experimental data were obtained from instrumented indentation tests on unfrozen femoral cartilage collected and studied in the day following the prosthetic hip surgery pose. By using an inverse method coupled with a numerical modeling (FEM) of all experimental data of the indentation tests, the viscoelastic properties of the two states were quantified.
\end{abstract}

Mean values of viscoelastic parameters were significantly lower for OA cartilage than normal (instantaneous and relaxed tension moduli, viscosity coefficient). Based on the results and in the thermodynamic framework, a constitutive viscoelastic model taking into account the degree of osteoarthritis as an internal variable of damage is proposed. The isotropic phenomenological viscoelastic model including degradation provides an accurate prediction of the mechanical response of the normal human cartilage and OA cartilage with advanced coxarthrosis but should be further validated for intermediate degrees of osteoarthritis. 


\section{Introduction}

Articular cartilage (AC) is the thin layer $(0.5-5.0 \mathrm{~mm}$ thick) of hydrated soft tissue covering the articulating bony ends in diarthrodial joints. It plays a vital role in the function of the musculoskeletal system by allowing almost frictionless motion to occur between the articular surfaces of a diarthrodial joint. Furthermore, it distributes the loads over a large contact area, thereby minimizing the contact stress, and dissipates the energy associated with dynamic loads (Mow et al., 1993).

\subsection{Normal articular cartilage}

$\mathrm{AC}$ can be considered as a solid matrix, saturated with water and mobile ions. The solid matrix consists of cartilage cells (chondrocytes) embedded in an extracellular matrix. The major components of the extracellular matrix are collagen molecules and negatively charged proteoglycans. The mechanical properties of cartilage depend primarily on the properties of the extracellular matrix. Composition, maintenance and gradual turnover of the matrix depend on the biosynthetic activity of chondrocytes (Maroudas, 1975).

Many studies have been conducted on the mechanical properties of cartilage (Wilson et al., 2005). It is generally accepted that, for a correct description of the mechanical behavior of $\mathrm{AC}$, an anisotropic, inhomogeneous and viscoporoelastic model should be used. Concurrent viscoelasticity and poroelasticity effects have been observed in articular cartilage and in poroviscoelastic model both types are included (DiSilvestro et al., 2001). Viscoelasticity results from the conformational change of macromolecules (fluid flow-independent), and poroelasticity results from the migration of small molecules (fluid flow-dependent). For articular cartilage the viscoelastic relaxation time (material-specific) is about $10 \mathrm{~s}$ and the poroelasticic relaxation time is above $1000 \mathrm{~s}$ in macro length scale. These values allow the classification of observations made with different lengths (radius of contact in an indentation test) and times (Hu et al., 2012). 
The objective of this study is to propose a model of articular cartilage taking into account loading rate and degree of osteoarthritis that it can be easily used in predictive numerical simulations of the hip joint behavior during daily various activities (Pustoc'h and Cheze, 2009). For this application, the observation time is approximately in same order of magnitude as the viscoelastic relaxation time and much lower than the poroelastic relaxation time (viscoelasticity relaxing and poroelasticity unrelaxed). For this reason, only viscoelastic model is used in this study, unlike various recent studies that are in different observation time and/or length (Gupta et al., 2009; Keenan et al., 2009; Miller et al., 2006).

\subsection{Cartilage damage due to osteoarthritis}

Osteoarthritis (OA) is the most common degenerative disease of human AC, especially in the population aged over 65 years (Hamerman, 1995). It is characterized by an extracellular matrix damage and an important loss in tissue cellularity (Vignon et al., 1974).

Several models were used to analyze the mechanical behavior of healthy and degenerated cartilage (Korhonen et al., 2003; DiSilvestro et al., 2002; Mäkelä et al., 2012). However, the initiation and progression of cartilage degeneration associated with experimental results on fresh normal human cartilage and osteoarthritis has so far not been studied and modeled. Understanding the mechanical behavior of damaged cartilage and associated parameters allows, through appropriate computational modeling, to better understand the beginning of some diseases such as osteoarthritis and efficiently analyze the pressure distribution in the joint.

Cartilage damage due to osteoarthritis is believed to be mechanically induced and the mechanical properties of cartilage tissue are strongly related to the OA stage of cartilage (Kleemann and al. 2005). Nonetheless, the initial event that triggers the pathological process of cartilage degeneration is still unknown. In order to investigate the initiation and the evolution of damage due to osteoarthritis, a behavior model must be determined with a damage variable which represents OA level. 


\subsection{Indentation testing to characterize articular cartilage}

Basically, instrumented indentation testing is a mechanical characterization process designed to determine the materials properties by putting an indenter in the surface of a material sample.

Indentation has been commonly used in testing the mechanical properties of articular cartilage at the macro, micro and nanoscales, and its loading conditions is considered more relevant to the physiological condition.

Elastic properties may be obtained from the measurements of the indentation load $P(t)$ versus the penetration depth $h(t)$ from the well-known equation for spherical indentation with the assumption of purely elastic solids (Johnson, 1971). It should be noted that unlike in simple tension or compression tests, in indentation test, the two material constants $E$ (Young's modulus) and $v$ (Poisson's ratio) are coupled in the indentation load-deflection relations, and additional independent tests are generally needed to uncouple them (Jin and Lewis, 2004). It has been shown that human articular cartilage exhibits viscous behavior during indentation and that it makes the analysis of the load-penetration curve more difficult. Moreover, it should be noted that viscous phenomena introduce errors when traditional elastic-plastic analysis of indentation data is used and time-dependence is ignored (Oliver and Pharr, 1992). Linear viscoelastic analytical solutions of indentation on a semi-infinite solid with a spherical-tip indenter developed by the method of functional equations are available for the load relaxation, creep tests (Cheng et al., 2005) and harmonic loading (Argatov et al., 2013), but the direct identification of the flow stress curve using an analytical model is impossible for more general loading and non linear behavior. In this paper, an inverse method is used to identify the parameters of the constitutive law. The identification is based on optimization techniques to adjust material parameters in order that the calculated response obtained by numerical modeling (Finite Element Method) matches the measured one.

The aim of this study is to identify the viscoelastic parameters of normal and OA femoral head cartilage on four distinct areas using instrumented indentation testing coupled with an identification method by the way of a numerical approach. The experimental part of this study is based on the preparation of human cartilage samples (normal and OA) and indentation tests. The 
numerical part is based on the simulation of indentation experiments by the finite element method coupled with an optimization algorithm to minimize the error between the model and experiments. The identifiability analysis of the model parameters is also proposed.

Analysis results allow to propose a single phase viscoelastic model with an internal damage variable in the thermodynamic framework. This damaged model is a good representation of the viscoelastic behavior in the two states (normal and OA) and provides a prediction of the intermediate states.

\section{Materials and methods}

\subsection{Cartilage sampling}

Samples of normal human cartilage from femoral head were obtained during hip replacement surgery from 6 patients exclusively with femoral neck fracture and showed no other pathology.

Samples of OA human cartilage from femoral head were obtained during surgery from 4 patients with clinical and radiological features of advanced coxarthrosis (Table 1).

These specimens were removed immediately after surgery from four study areas (superior, inferior, posterior and anterior) delimited by the surgeon at the end of the operation. The samples were then stored at $4^{\circ} \mathrm{C}$ in a solution of Phosphate Buffered Saline (PBS) until the mechanical tests that did not exceed 24 hours after collection. Samples have a thickness of $8 \mathrm{~mm}$, a length of $25 \mathrm{~mm}$ and a width of $15 \mathrm{~mm}$ (subchondral bone and a small thickness of cancellous bone were preserved). For OA femoral head, the samples were carried out in areas where enough cartilage remained.

A total of 29 samples were analyzed ( 24 normal and 5 OA). To validate the method, other samples with the same preparation method were also used and some results are presented to illustrate the mechanical behavior of the material and the relevance of the identification process. 


\subsection{Indentation}

\subsubsection{Experimental testing}

The tests were performed by using an instrumented micro-indenter system developed at DMA/FEMTO-ST institute that is able to measure the indentation load $P$ and the penetration depth $h$ in various mechanical modes. The principle of this testing method is presented in Fig. 1 . A spherical and impermeable stainless steel indenter (radius $R=1.5 \mathrm{~mm}$ ) was used during the experiments (Fig. 2).

Three consecutive measures spaced by $2 \mathrm{~mm}$ were performed on each sample (random measurements between indentation). Tests were conducted in load-unload configuration with a depth of less than $250 \mu \mathrm{m}$ and a rate of about $5 \mu \mathrm{m} / \mathrm{s}$. Load-unload cycle analysis can be used to access to viscoelastic properties (Qasmi et al., 2004) and it seems a realistic test for the main application of the model. The load rate $(5 \mu \mathrm{m} / \mathrm{s})$ fully activates viscoelastic phenomena and was chosen to keep experimental observation time much lower than poroelastic relaxation time for an indentation depth about $10 \%$ of the cartilage thickness.

To validate model, other tests have been also carried out on other samples: load-unload (rate from $1 \mu \mathrm{m} / \mathrm{s}$ to $40 \mu \mathrm{m} / \mathrm{s})$, creep and relaxation.

\subsubsection{Viscoelastic constitutive law}

Articular cartilage can be characterized as an isotropic viscoelastic material with no interstitial fluid flow during short time response. Isotropic viscoelastic constitutive law is based on the idea that the dilatational components of the stress tensor $\sigma_{k k}$ which involves the volumetric compression, and the deviatoric part $s_{i j}$ which only accounts for shape modifications, are decoupled. Thus, the constitutive law can be written as

$$
\dot{s}_{i j}+\frac{E+H}{\eta} S_{i j}=\frac{E}{(1+v)} \dot{e}_{i j}+\frac{E}{(1+v)} \frac{H}{\eta} e_{i j}
$$




$$
\dot{\sigma}_{k k}+\frac{E+H}{\eta} \sigma_{k k}=\frac{E}{(1-2 v)} \dot{\varepsilon}_{k k}+\frac{E}{(1-2 v)} \frac{H}{\eta} \varepsilon_{k k}
$$

with

$$
S_{i j}=\sigma_{i j}-\frac{1}{3} \delta_{i j} \sigma_{k k}, e_{i j}=\varepsilon_{i j}-\frac{1}{3} \delta_{i j} \varepsilon_{k k}
$$

In these equations, $E$ is the instantaneous Young's modulus and $H$ a tension modulus connected to the relaxed Young's modulus $E^{\infty}=E H /(E+H) . v$ is the Poisson' ratio and $\eta$ the viscosity coefficient of the model. $\delta_{i j}$ is the second order unity tensor, $s_{i j}$ and $e_{i j}$ represent the stress and strain deviatoric tensors. $\sigma_{i j}$ and $\varepsilon_{i j}$ are the stress and the strain tensors respectively. The above equations correspond to the standard linear solid model as shown in Fig. 3.

It should be noted here that the Poisson ratio is assumed to be constant. This assumption is validated experimentally from indentation test (Jin and Lewis, 2004). It also notices that in tension, Eq. (1) and (2) are summarized by the following expression

$$
\dot{\sigma}_{11}+\frac{1}{\tau} \sigma_{11}=E \dot{\varepsilon}_{11}+\frac{E^{\infty}}{\tau} \varepsilon_{11}
$$

Where $E^{\infty}=E H /(E+H)$ and $\tau=\eta /(E+H)$ are, respectively, the relaxed tension modulus and the relaxation constant.

The identification of the four parameters model $\boldsymbol{\theta}={ }^{T}[E, v, H, \eta]$ is required. The identification of these material parameters was performed for each sample by using an inverse method from experimental results and numerical modeling of the indentation test. An identifiability analysis was performed to determine uncertainties on the obtained parameters.

\subsubsection{Numerical testing}

The indentation test was modeled in a 2D axisymmetric representation with the ANSYS ${ }^{\circledR}$ finite element software (Fig. 4). The indenter is considered as a rigid semi-circular arc. Cartilage thickness $h_{c}$ is adapted to samples (from $1 \mathrm{~mm}$ to $3.2 \mathrm{~mm}$ ). 
No friction between indenter/cartilage was considered. Thicknesses and mechanical behavior of subchondral $h_{s b}$ and cancellous bones $h_{c b}$ were taken into account in the model and considered as elastic and isotropic $\left(E_{s b}=2000 \mathrm{MPa}, v_{s b}=0.3, E_{c b}=600 \mathrm{MPa}, v_{c b}=0.2\right)$. The low sensitivity of these parameters on the loading-penetration curve $(\mathrm{P}-\mathrm{h})$ was tested.

Substrat's inferior part was embedded. The contact algorithm between rigid indenter and cartilage was the augmented Lagrangian method. The considered material behavior is a viscoelastic model detailed in the previous section. An implicit method with non-linear geometric consideration is used with higher order 2-D elements. The mesh density is defined in order that the smallest elements are localized in the contact region. A convergence analysis has been performed in order to avoid any mesh influence.

\subsection{Inverse method for parametric identification}

\subsubsection{A least-squares error minimization approach}

The identification of material parameters can be seen as an inverse formulation. In this study, the main idea is to simulate the performed experiment (load-unload indentation with a constant rate displacement), by adapting the 4 material parameters $\boldsymbol{\theta}={ }^{T}\left[\theta_{1}, \theta_{2}, \theta_{3}, \theta_{4}\right]={ }^{T}[E, v, H, \eta]$ in order to numerically obtain the same results as the experimental ones (Fig. 5). This approach consists of an optimization problem where the objective is to minimize the gap between the experimental $P_{E}(t)$ and the numerical results $P_{N}(\boldsymbol{\theta}, t)$, whatever the time variable $t$ belonging to the period of the experimental test. The gap (or the residuals) between the experimental and the numerical results can be defined as

$$
f(\boldsymbol{\theta})=\frac{1}{2 N \max _{t \in\left[0, t_{N}\right]}\left|P_{E}(t)\right|} \sum_{i=1}^{N}\left[P_{E}\left(t_{i}\right)-P_{N}\left(\boldsymbol{\theta}, t_{i}\right)\right]^{2}
$$

In previous equation, the $i^{\text {th }}$ data points corresponding to the acquisition times $t_{i}$. The minimization problem can be written formally: 


$$
\boldsymbol{\theta}^{*}={ }^{T}[E, \nu, H, \eta]=\underset{\boldsymbol{\theta} \in\left[\boldsymbol{\theta}^{-}, \boldsymbol{\theta}^{+}\right]}{\arg \min } f(\boldsymbol{\theta})
$$

Where $\boldsymbol{\theta}^{*}$ is the solution of the identification problem. $\boldsymbol{\theta}^{-}$and $\boldsymbol{\theta}^{+}$are the minimum and maximum limits on the material parameters. The minimization problem was solved for each cartilage sample with the optimization software MIC2M (Richard, 2000) by considering an algorithm based on the Levenberg-Marquardt method. From numerical modeling of the indentation test and experimental results, this software was able to write the functional (5) to be minimized.

\subsubsection{Identifiability analysis}

Samples preparation follows the procedure describes in section 2.1. Parameters were identified from a loading-unloading experimental indentation test with a rate displacement $\dot{h} \approx 5 \mu \mathrm{m} / \mathrm{s}$ following the procedure describes in the previous section. The solid lines in Fig. 6 are associated to the viscoelastic model with the parameters obtained by the identification procedure. The resulting parameters are $E^{*}=9.3 \mathrm{MPa}, v^{*}=0.49, H^{*}=2.0 \mathrm{MPa}$ and $\eta^{*}=87.6 \mathrm{MPa}$.s .

Fig. 6 shows a good correlation between simulation and experiment, but the information contained in the available experimental data must be evaluated more precisely to determine if they are suitable for a reliable parameter estimation, mainly due to the uncertainty of the Poisson's ratio.

All techniques of identifiability analysis are based on local sensitivity functions. These functions quantify the relation between the outputs and the parameters of the model. In this study, the sensitivity function is mathematically defined by

$$
S_{i j}=\left.\frac{\partial P_{N}\left(\boldsymbol{\theta}, t_{i}\right)}{\partial \theta_{j}}\right|_{\boldsymbol{\theta}^{*}} \frac{\theta_{j}^{*}}{P_{N}\left(\boldsymbol{\theta}^{*}, t_{i}\right)}
$$

The sensitivity ranking of the $j^{\text {th }}$ parameter is done by using the relation 
$\delta_{j}=\frac{1}{N} \sum_{i=1}^{N}\left|S_{i j}\right|$

Fig. 7 shows the sensitivity of the response in relation with the different parameters from indentation test. Each sensitivities $\delta_{j}$ are equivalent in term of magnitude. Sensitivity to other parameters of the model has been calculated. The sensitivity to the cartilage thickness $h_{c}$ (adjusted for each sample) is equal to 0.2 while the others are negligible $\left(h_{s b}, h_{c b}, E_{s b}, \ldots\right)$.

The poor identifiability of the model parameters can be due to a small sensitivity of the model results to a parameter, or by a linear approximation dependence of sensitivity functions on the results with respect to the parameters. It is evaluated through an indicator which is a measure of the shape of the confidence region

$$
J_{E}=\lambda_{\max } / \lambda_{\min }
$$

where $\lambda_{\max }$ and $\lambda_{\min }$ are respectively the largest and the smallest eigenvalue of the Fisher's Information Matrix $\mathbf{F}={ }^{T} \mathbf{S S}$, defined from normalized sensitivities (7) of the set of considered parameters. According to Gujarati (2004), a low value of $J_{E}<100$ indicates a low collinearity (good identifiability) and a high value $\left(J_{E}>1000\right)$ indicates a very high collinearity (poor identifiability).

Table 2 shows a moderate correlation between the parameters for $k=4\left(J_{E} \approx 300\right)$. It is therefore difficult to identify the 4 parameters. At the opposite, the calculation of $J_{E}$ for $k=3$ presents a good identifiability of $\left[E^{*}, H^{*}, \eta^{*}\right]$ and $\left[E^{*}, v^{*}, \eta^{*}\right]$.

In the indentation test, it is well known that the elastic modulus is correlated with the Poisson ratio through the indentation modulus and variability of results may be limited by the following assumption that the value of Poisson's ratio can vary from 0 to 0.5 . To estimate the error on the parameters obtained, an identification was performed with $v=0$ and the resulting parameters set is equal to: $E^{*}=12.1 \mathrm{MPa}, H^{*}=2.7 \mathrm{MPa}, \eta^{*}=112.7 \mathrm{MPa}$.s . This solution leads to an error on the cost function (5) equivalent to the first identification results. It can be estimated that the error 
parameter is less than 30\%. In practice, the Poisson's ratio is not set. It will be observed that this uncertainty is lower than inter and intra individual variability. Nevertheless for almost samples (normal and $\mathrm{OA}$ ), the algorithm converges to a value of about $v=0.47$. This result is closed to the results obtained by Jin and Lewis (2004). They consider different indenter radius to access to this value.

\subsection{Statistical analysis}

For normal and OA cartilage, a variance analysis was performed to compare each viscoelastic parameters between the different areas. To compare each viscoelastic parameters between the normal and OA cartilage, a t-test was performed. For statistical tests, a significance level of 0.05 was used.

\section{Results and discussion}

\subsection{Identification Results}

A total of 29 samples were analyzed (24 normal and 5 OA). The different results obtained by using the identification procedure defined in section 2.3. are summarized in Table 3 and Table 4.

\subsubsection{Normal cartilage}

24 samples were analyzed from normal femoral heads. The means and standard deviations values are defined in Table 5. The mean values observed for the three considered parameters are respectively $E=10.9 \mathrm{MPa}, v=0.47, H=2.2 \mathrm{MPa}$ and $\eta=218.7 \mathrm{MPa} . \mathrm{s}$. This leads to a relaxed tensile modulus $E^{\infty}=1.8 \mathrm{MPa}$ and a relaxation constant $\tau=16.7 \mathrm{~s}$.

No significant differences could be put in evidence in mean values of the viscoelastic parameters $E, H$, and $\eta$ between the different areas ( $\mathrm{p}>0.75$ ). However, a significant difference was observed for Poisson's ratio $(\mathrm{p}<0.05)$. 


\subsubsection{Osteoarthritis cartilage}

5 samples were analyzed from OA femoral heads. Table 5 shows the means and standard deviations obtained. The mean values observed for the three considered parameters are respectively $E=3.4 \mathrm{MPa}, v=0.47, H=0.6 \mathrm{MPa}$ and $\eta=36.0 \mathrm{MPa}$.s. This leads to a relaxed tensile modulus $E^{\infty}=0.5 \mathrm{MPa}$ and a relaxation constant $\tau=9.0 \mathrm{~s}$.

These parameters values obtained are close to the results proposed by Juras et al. (2011) for OA human femoral condyles (knee cartilage). Values of $E, E^{\infty}$ and $\tau$ ranged respectively from 2.5 to $10.7 \mathrm{MPa}$ (mean: $4 \mathrm{MPa}$ ), 0.1 to $2.9 \mathrm{MPa}$ (mean: $0.8 \mathrm{MPa}$ ), and 3.8 to $22.6 \mathrm{~s}$ (mean: $11.0 \mathrm{~s}$ ).

No significant differences could be put in evidence in mean values of viscoelastic parameters $E$, $H$, and $\eta$ between the different areas ( $\mathrm{p}>0.36)$. However, a significant difference was observed for Poisson's ratio $(\mathrm{p}<0.05)$.

\subsubsection{Comparison normal/OA}

The mean values of viscoelastic parameters $E, H$ and $\eta$ were significantly lower for OA cartilage than normal ( $\mathrm{p}=0.002,0.025,0.013$ respectively). However, no difference for $v$ was observed $(\mathrm{p}=0.953)$.

The $E$ and $H$ moduli are about 3.5 times lower for the OA cartilage than the normal cartilage but it is interesting to note that the $E / E^{\infty}$ ratio does not change with osteoarthritis. On the viscosity coefficient $\eta$ and the relaxation constant $\tau$, they are respectively six and twice lower for the OA cartilage than the normal cartilage, but the uncertainty in these values is quite important, due to high inter-individual and intra-individual variability.

The means values of cartilage thickness differed between the inferior area $(1.61 \mathrm{~mm})$ and superior area $(2.97 \mathrm{~mm})$. These results are in agreement with the literature (Kurrat and Oberländer, 1978). No significant correlation between thickness and the identified viscoelastic parameters is observed. 


\subsection{A viscoelastic model including degradation}

In this section, an isotropic phenomenological viscoelastic model used to provide an accurate prediction of the mechanical response of human normal and OA cartilage is presented.

In the context of thermodynamics with internal variables (Lemaitre and Chaboche, 1990) for an isothermal process, the continuum damage mechanics concepts developed by the Lemaître's school (Lemaitre et Desmorat, 2005) are considered. Starting from the early proposition of Kachanov (1958) and Rabotnov (1969), a scalar damage variable $D$ which characterizes the degree of material degradation is introduced

$$
\tilde{\boldsymbol{\sigma}}=\frac{\boldsymbol{\sigma}}{1-D}
$$

where $\boldsymbol{\sigma}$ is the Cauchy stress tensor and $\tilde{\boldsymbol{\sigma}}$ the effective stress tensor. The damage variable $D$ may be interpreted as an indirect measure of degree of osteoarthritis and it is assumed that $0 \leq D \leq D_{c} \leq 1$, where $D_{c}$ is the critical damage parameter defining the local failure, here defined as the degree of osteoarthritis corresponding to advanced coxarthrosis. By applying the elastic strain equivalence hypothesis (Lemaitre, 1978), the strain behavior of damaged model material is represented by the constitutive equation of virgin material which stress is simply replaced by the effective stress such as:

$$
\boldsymbol{\varepsilon}^{e}=\mathbf{C}^{-1}: \tilde{\boldsymbol{\sigma}}=\tilde{\mathbf{C}}^{-1}: \boldsymbol{\sigma}
$$

where $\boldsymbol{\varepsilon}^{e}$ is the elastic strain and $\mathbf{C}$ the elastic constitutive tensor for the normal cartilage which can be written in matrix notation as a function of the bulk modulus $K$ and the shear modulus $G$

$$
[\mathbf{C}]=\left[\begin{array}{cccccc}
K+4 G / 3 & K-2 G / 3 & K-2 G / 3 & 0 & 0 & 0 \\
K-2 G / 3 & K+4 G / 3 & K-2 G / 3 & 0 & 0 & 0 \\
K-2 G / 3 & K-2 G / 3 & K+4 G / 3 & 0 & 0 & 0 \\
0 & 0 & 0 & G & 0 & 0 \\
0 & 0 & 0 & 0 & G & 0 \\
0 & 0 & 0 & 0 & 0 & G
\end{array}\right]
$$

with 


$$
K=\frac{E}{3(1-2 v)} \text { and } G=\frac{E}{2(1+v)}
$$

$E$ is the virgin (undamaged) instantaneous modulus (Young's modulus). $\tilde{\mathbf{C}}$ is the elastic constitutive tensor for the damaged material which can be written by using (10) and (11) as follows

$$
\tilde{\mathbf{C}}=(1-D) \mathbf{C}
$$

Assuming that the Poisson's ratio is unaffected by the damage process, the damaged bulk and shear moduli can be written as a function of the instantaneous damaged Young's modulus $\tilde{E}$ :

$$
\tilde{K}=\frac{\tilde{E}}{3(1-2 v)}, \tilde{G}=\frac{\tilde{E}}{2(1+v)}
$$

The strain partition assumption is used. The total strain is then partitioned in an elastic part $\boldsymbol{\varepsilon}^{e}$ (instantaneous reversible strain) and a viscous part $\boldsymbol{\varepsilon}^{v}$ (time-dependent reversible strain):

$$
\varepsilon=\varepsilon^{e}+\varepsilon^{v}
$$

The state variables can be divided in observable variables and internal variables as defined in Table 6. The $\boldsymbol{\alpha}$ and $\mathbf{X}$ tensors are associated to viscous phenomena.

The standard generalized framework (Halphen et Nguyen, 1975) assumes that the mechanical behavior can be obtained when two potentials are defined: a free energy density $\psi$ and a dissipation potential $\Omega$. By applying the hypothesis that elasticity and viscous behaviors are uncoupled, the free energy is proposed as the following expression

$$
\rho \psi\left(\boldsymbol{\varepsilon}^{e}, \boldsymbol{\alpha}, D\right)=\frac{1}{2}(1-D)\left(\boldsymbol{\varepsilon}^{e}: \mathbf{C}: \boldsymbol{\varepsilon}^{e}+\frac{H}{E} \boldsymbol{\alpha}: \mathbf{C}: \boldsymbol{\alpha}\right)
$$

Where $\rho$ is the mass density. State laws can be defined by: 


$$
\begin{aligned}
& \boldsymbol{\sigma}=\rho \frac{\partial \psi}{\partial \boldsymbol{\varepsilon}^{e}}=(1-D) \mathbf{C}: \boldsymbol{\varepsilon}^{e} \\
& \mathbf{X}=\rho \frac{\partial \psi}{\partial \boldsymbol{\alpha}}=(1-D) \frac{H}{E} \mathbf{C}: \boldsymbol{\alpha} \\
& Y=\rho \frac{\partial \psi}{\partial D}=-\frac{1}{2}\left(\boldsymbol{\varepsilon}^{e}: \mathbf{C}: \boldsymbol{\varepsilon}^{e}+\frac{H}{E} \boldsymbol{\alpha}: \mathbf{C}: \boldsymbol{\alpha}\right)
\end{aligned}
$$

Based on the experimental results, the following dissipation potential is introduced

$$
\Omega=\frac{1}{2 \eta}(\tilde{\boldsymbol{\sigma}}-\tilde{\mathbf{X}}):(\tilde{\boldsymbol{\sigma}}-\tilde{\mathbf{X}})+\Upsilon(Y)
$$

The potential $\Upsilon$ can be integrated into the evolution of creep damage and fatigue. Based on this potential $\Omega$, the evolution of internal variables is expressed as

$$
\begin{aligned}
& \dot{\boldsymbol{\varepsilon}}^{v}=\frac{\partial \Omega}{\partial \boldsymbol{\sigma}}=\frac{\boldsymbol{\sigma}-\mathbf{X}}{\eta(1-D)^{2}}=\frac{\boldsymbol{\sigma}-\mathbf{X}}{\tilde{\eta}} \\
& \dot{\boldsymbol{\alpha}}=-\frac{\partial \Omega}{\partial \mathbf{X}}=\dot{\boldsymbol{\varepsilon}}^{v} \\
& \dot{D}=-\frac{\partial \Omega}{\partial Y}=-\frac{\partial \Upsilon}{\partial Y}
\end{aligned}
$$

From a rheological point of view the model proposed here can be represented by a standard linear solid model with damage and damaged parameters can be defined using the above equations:

$$
\begin{aligned}
& \tilde{E}=(1-D) E ; \tilde{H}=(1-D) H ; \tilde{\eta}=(1-D)^{2} \eta \\
& \tilde{\tau}=\tilde{\tau}(1-D) \text { and } \tilde{E}^{\infty}=\tilde{E}^{\infty}(1-D)
\end{aligned}
$$

$E$ and $H$ are about 3.5 times lower OA cartilage than normal, the critical damage corresponding to advanced coxarthrosis is $D_{c}=1-1 / 3.5=0.71$. The comparison between the proposed model and the experiments are presented in Fig. 8. A good correlation between model and experimental 
data is observed. The proposed model must be validated for intermediate degrees of osteoarthritis.

\section{Conclusions}

By using an inverse method coupled with a finite element method of the indentation test, the effects of osteoarthritis (OA) on the viscoelastic behavior of the human hip femoral cartilage is quantified.

In the normal and OA cartilage, no significant differences could be put in evidence between the different areas and the results showed a relative homogeneity of the viscoelastic parameters within each femoral head. However, it reveals a high intra and inter-individual variability.

Mean values of viscoelastic parameters were significantly lower for the OA cartilage than the normal: $E$ and $H$ moduli are about 3.5 times lower for OA cartilage than normal cartilage and the viscosity coefficient $\eta$ is about six times lower.

The proposed isotropic phenomenological viscoelastic model provides an accurate prediction of the mechanical response of the normal and OA cartilages with advanced coxarthrosis.

Relationships between the viscoelastic material parameters $E, H, \eta$ and the internal variable of damage $D$ which represents the degree of osteoarthritis are validated for the two states, $D=0$ (normal cartilage) and $D=D_{c}=0.71$ (OA cartilage with advanced coxarthrosis) but it must be validated for intermediate degrees of osteoarthritis. Magnetic resonance imaging (MRI) offers excellent soft tissue contrast and it has been developed for noninvasive assessment of the structure of articular cartilage. In recent studies, significant correlations were observed between MRI and mechanical parameters (especially Young's modulus). Therefore, MRI could be a powerful technique to access to the internal variable of damage (Lammentausta et al. 2006; Juras et al. 2009).

These viscoelastic model including degradation could be easily introduced in a predictive calculation of the hip joint to simulate the effects of osteoarthritis and loading rate on the contact areas, pressures, stresses, or others values like relative sliding velocity during various activities of daily life. 


\section{Acknowledgments}

We thank the Pr P. Garbuio for his help and all the Department of Orthopaedic Surgery of the University Hospital of Besançon for collecting femoral heads. The samples were cut at the Besançon anatomy laboratory. We also thank S. Mith, L. Carpentier and V. Gunes for their assistance on the indentation tests, P. Clément for the development of the experimental protocol and E. Fournier in the statistical analysis results. 


\section{REFERENCES}

Argatov, I., Daniels, A.U., Mishuris, G., Ronken, S., Wirz, D., 2013. Accounting for the thickness effect in dynamic spherical indentation of a viscoelastic layer: Application to non-destructive testing of articular cartilage. Eur J Mech A/Solids 37, 304-317.

Cheng, L., Xia, X., Scriven, L.E., Gerberich, W.W., 2005. Spherical-tip indentation of viscoelastic material, Mech Mater 37, 213-226.

DiSilvestro, M.R., Suh, J.K., 2001. A cross-validation of the biphasic poroviscoelastic model of articular cartilage in unconfined compression, indentation, and confined compression. J Biomech 34(4), 519-25.

DiSilvestro, M.R., Suh, J.K., 2002. Biphasic poroviscoelastic characteristics of proteoglycan-depleted articular cartilage: simulation of degeneration. Ann Biomed Eng 30(6), 792-800.

Gujarati, D., 2004. Basic Econometrics, 4th Edition, McGraw-Hill/Irwin.

Gupta S., Lin J., Ashby P., Pruitt L., 2009. A fiber reinforced poroelastic model of nanoindentation of porcine costal cartilage: a combined experimental and finite element approach. J Mech Behav Biomed Mater 2(4), 326-337.

Halphen, B., Nguyen, Q. S., 1975. Sur les matériaux standards généralisées. J. de Mécanique 14, 39-63.

Hamerman D., 1995. Clinical implications of osteoarthritis and aging. Ann. Rheum. Dis. 54(2), 82-85.

Hu, Y., Suo, Z., 2012. Viscoelasticity and poroelasticity in elastomeric gels. Acta Mechanica Solida Sinica 25(5), 441-458.

Jin, H., Lewis, J.L., 2004. Determination of Poisson's ratio of articular cartilage by indentation using different-sized indenters. J Biomech Eng 126(2), 138-145.

Johnson, K. L., Kendall, K., Roberts, A. D, 1971. Surface energy and the contact of elastic solids, Proc. R. Soc. Lond. A. 324, 301-313.

Juras, V., Bittsansky, M., Majdisova, Z., Szomolanyi, P., Sulzbacher, I., Gabler, S., Stampfl, J., Schuller, G., Trattnig, S., 2009. In vitro determination of biomechanical properties of human articular cartilage in osteoarthritis using multi-parametric MRI. J. Magn. Reson. 197, 40-47.

Kachanov, L., 1958. Time of the Rupture Process under Creep Conditions. Isv. Akad. Nauk. SSR. Otd Tekh. Nauk., $8,26-31$. 
Keenan K.E., Kourtis L.C., Besier T.F., Lindsey D.P., Gold G.E., Delp S.L., Beaupre G.S., 2009. New resource for the computation of cartilage biphasic material properties with the interpolant response surface method. Comput Methods Biomech Biomed Engin. 12(4), 415-422.

Kleemann, R.U., Krocker, D., Cedraro, A., Tuischer, J., Duda, G.N., 2005. Altered cartilage mechanics and histology in knee osteoarthritis: relation to clinical assessment (ICRS Grade), Osteoarthr. Cartil. 13, 958-963.

Korhonen, R.K., Laasanen, M.S., Toyras, J., Lappalainen, R., Helminen, H.J., Jurvelin, J.S., 2003. Fibril reinforced poroelastic model predicts specifically mechanical behavior of normal, proteoglycan depleted and collagen degraded articular cartilage. J Biomech 36(9), 1373-1379.

Kurrat, H.J., Oberländer, W., 1978. The thickness of the cartilage in the hip joint. J. Anat., 126, 145-155

Lammentausta E., Kiviranta P.,Nissi M.J., Laasanen M.S., Kiviranta I., Nieminen M.T., Jurvelin J.S., 2006. T2 Relaxation time and delayed gadolinium-enhancedMRI of cartilage (dGEMRIC) of human patellar cartilage at 1.5T and 9.4 T: relationships with tissue mechanical properties. J Orthop Res. 24(3), 366-374.

Lemaitre, J., 1978. Théorie mécanique de l'endommagement isotrope appliqué à la fatigue des métaux, HALPHEN B. et NGUYEN Q.S. (eds.), actes Matériaux et structures sous chargement cyclique, Association Amicale des Ingénieurs Anciens Elèves de I'ENPC, 133-144.

Lemaitre, J.; Chaboche, J.L., 1990. Mechanics of Solid Materials. Cambridge University Press.

Lemaitre, J., Desmorat, R., 2005. Engineering damage mechanics. Springer, Berlin.

Mäkelä, J.T., Huttu, M.R., Korhonen, R.K., 2012. Structure-function relationships in osteoarthritic human hip joint articular cartilage. Osteoarthr. Cartil. 20(11), 1268-77.

Maroudas, A. Biophysical chemistry of cartilaginous tissues with special reference to solute and fluid transport, 1975. Biorheology 12, 233-248.

Miller G.J., Morgan E.F., 2006. Use of microindentation to characterize the mechanical properties of articular cartilage: comparison of biphasic material properties across length scales. Osteoarthr. Cartil. 18(8), 1051-1057.

Mow, V.C., Ateshian, G.A., and Spilker, R.L., 1993. Biomechanics of diarthrodial joints: a review of twenty years of progress. J Biomech Eng 115, 460-467.

Oliver, W.C., Pharr, G.M., 1992. An improved technique for determining hardness and elastic modulus using load and displacement sensing indentation experiments. J Mater Res 7, 1564-1583.

Pustoc'h A., Cheze L., 2009. Normal and osteoarthritic hip joint mechanical behaviour : a comparison study. Med Biol Eng Comput 47(4), 375-383. 
Qasmi, M., Delobelle, P., Richard, F., Brun C., Fromm M., 2004. Viscoelastic mechanical properties determined by nanoindentation tests and its numerical modelling of polypropylene modified by $\mathrm{He}+$ particle implantation and $\mathrm{e}(-)$ irradiation, Prog Org Coat, 51(3), 195-204.

Richard, F., 2000. MIC2M Software, Modélisation et Identification du Comportement Mécanique des Matériaux, http://mic2m.univ-fcomte.fr.

Rabotnov, Y.N., 1969. Creep Problems in Structural Members. Amsterdam: North- Holland.

Vignon, E., Arlot, M., Meunier, P., Vignon, G., 1974. Quantitative histological changes in osteoarthritic hip cartilage: morphometric analysis of 29 osteoarthritic and 26 normal human femoral heads. Clin. Orthop. Relat. Res. $103,269-278$.

Wilson, W., van Donkelaar, C.C, van Rietbergen, R., Huiskes, R., 2005. The role of computational models in the search for the mechanical behavior and damage mechanisms of articular cartilage. Med Eng Phys 27, 810-826. 


\section{List of Figures}

Fig. 1 - Experimental instrumented indentation test.

Fig. 2 - Spherical indenter.

Fig. 3 - Standard linear solid model.

Fig. 4 - Finite element model of the indentation test $\left(h_{s b}=0.6 \mathrm{~mm}, h_{c}+h_{s b}+h_{c b}=8 \mathrm{~mm}\right)$.

Fig. 5 - Inverse method procedure.

Fig. 6 - Indentation curve, load $P$ applied to the material's surface vs. the penetration depth $h$ for a normal cartilage sample.

Fig. 7 - Parameter sensitivity to material parameters.

Fig. 8 - Viscoelastic parameters vs. Degree of OA (damage). $D=0$ (normal) and $D=D_{c}=0.71$ (advanced coxarthrosis). 


\section{List of Tables}

Table 1 - Some relevant characteristics of the normal subjects and patients with OA.

Table 2 - Identifiability measurement ( $<100$ good; $>1000$ poor).

Table 3 - Viscoelastic parameters for normal cartilage. *(MPa), **MPa.s

Table 4 - Viscoelastic parameters for OA cartilage. *(MPa), **MPa.s

Table 5 - Distribution of parameters $E, v, H$ and $\eta$ for normal and OA cartilage ( $n$ : number of samples, NC: Non Calculable, SD: Standard Deviation).

Table 6 - Thermodynamic variables. 


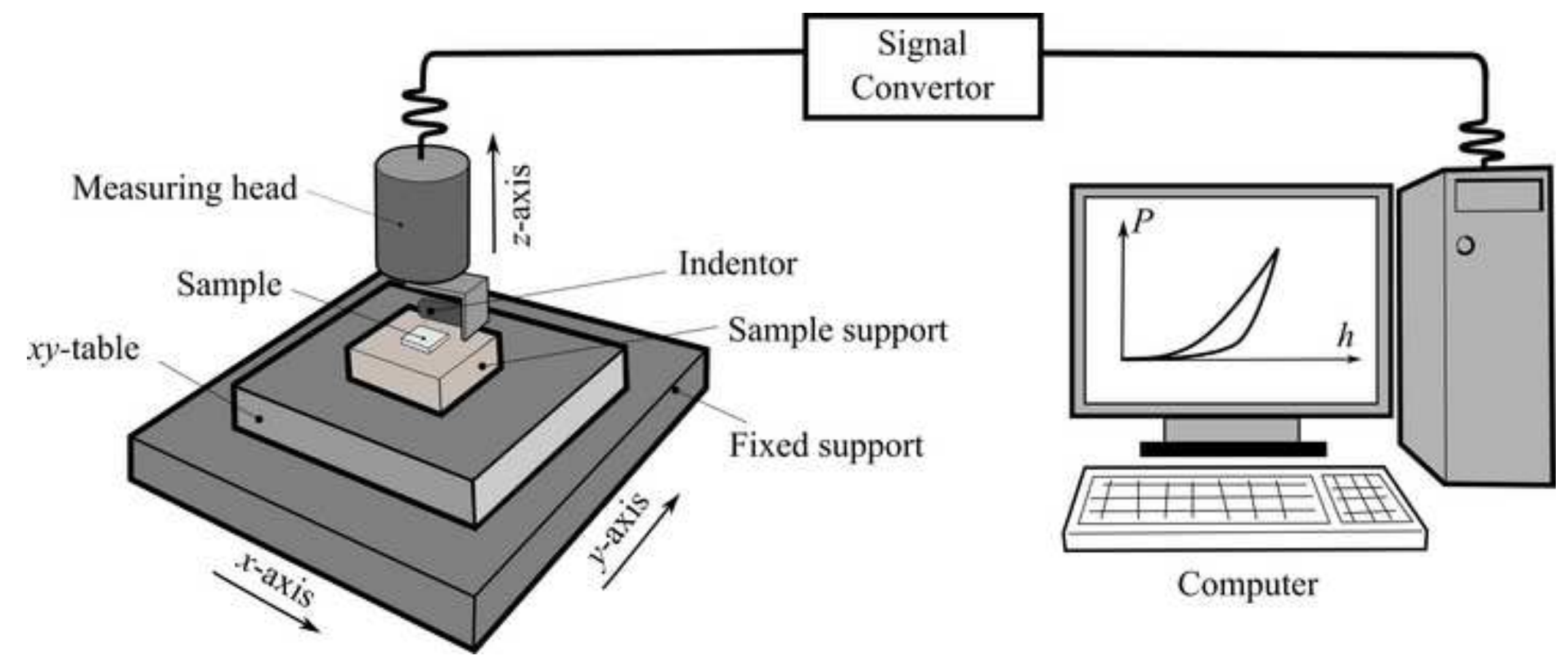




\section{Figure2}

Click here to download high resolution image

P

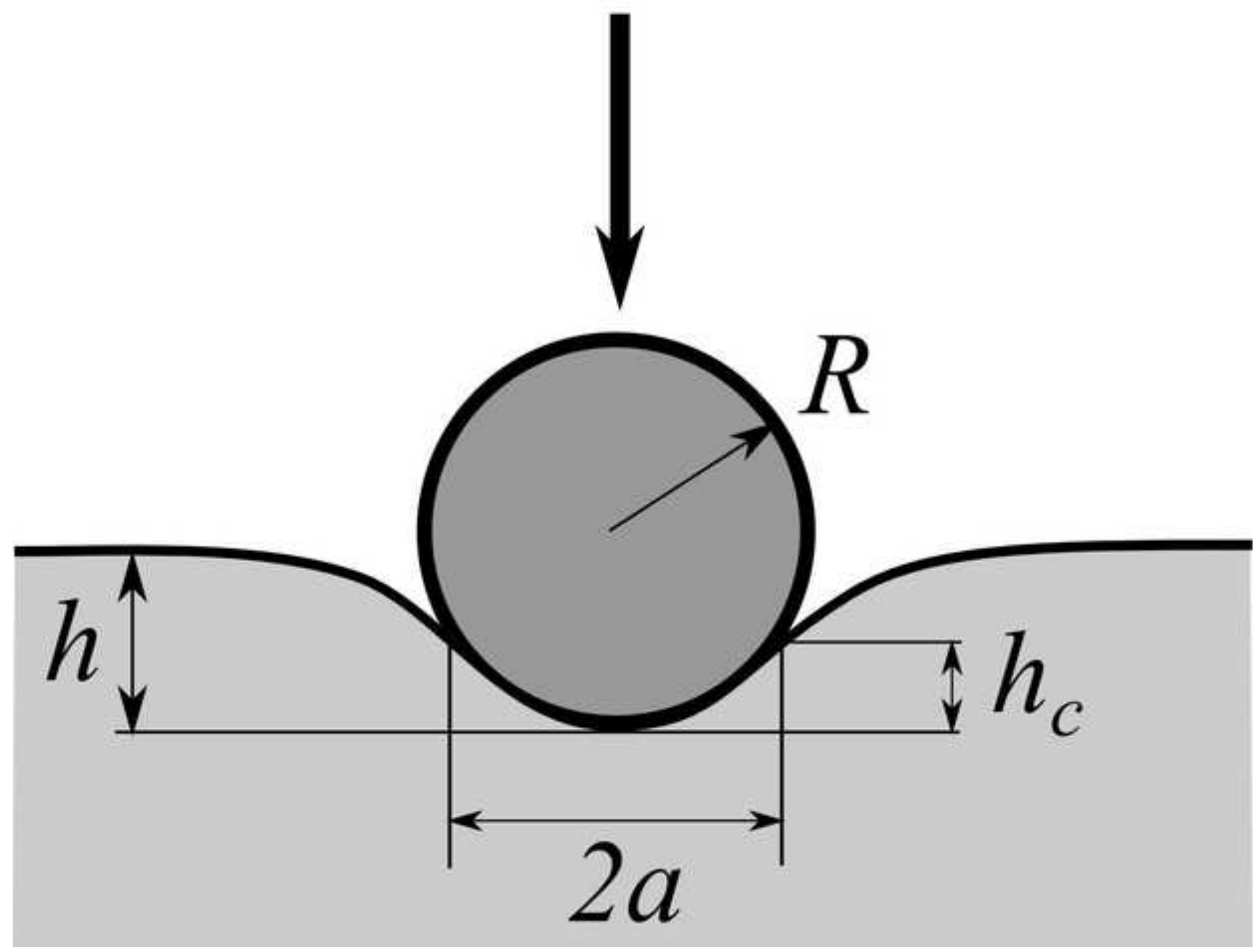




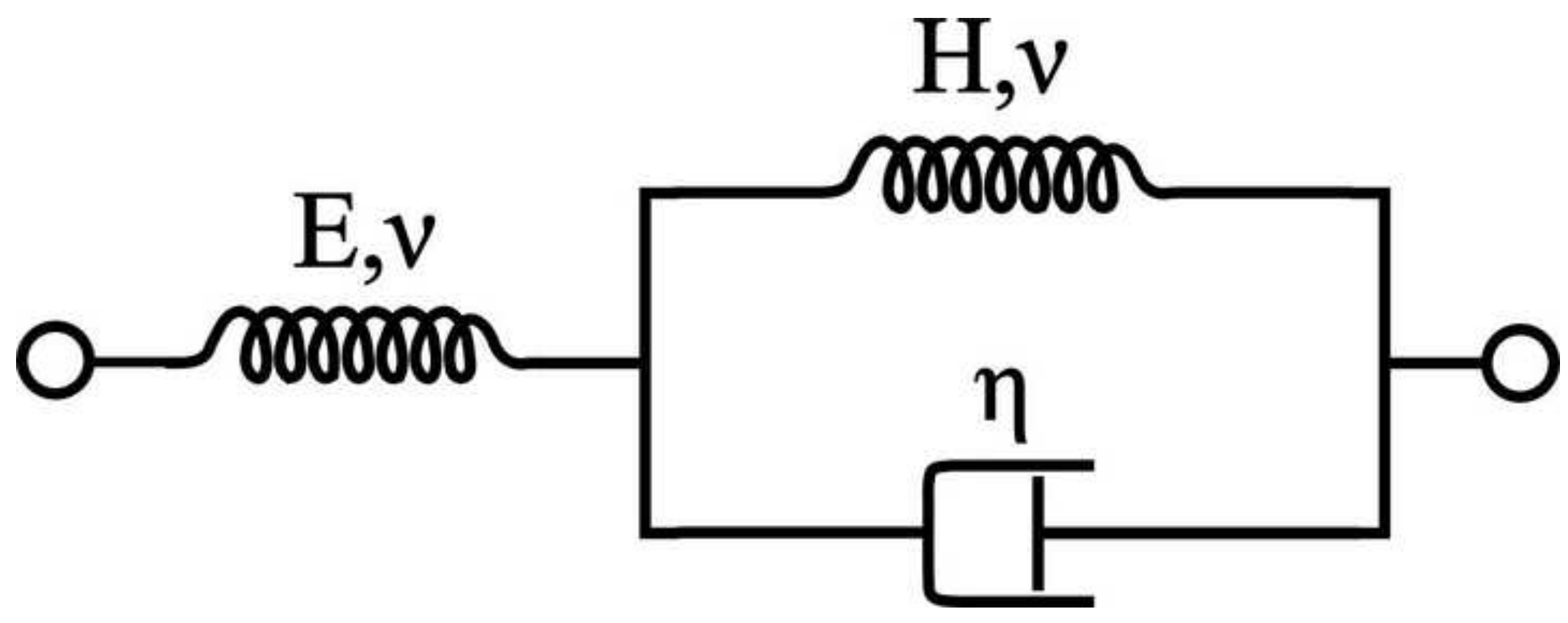




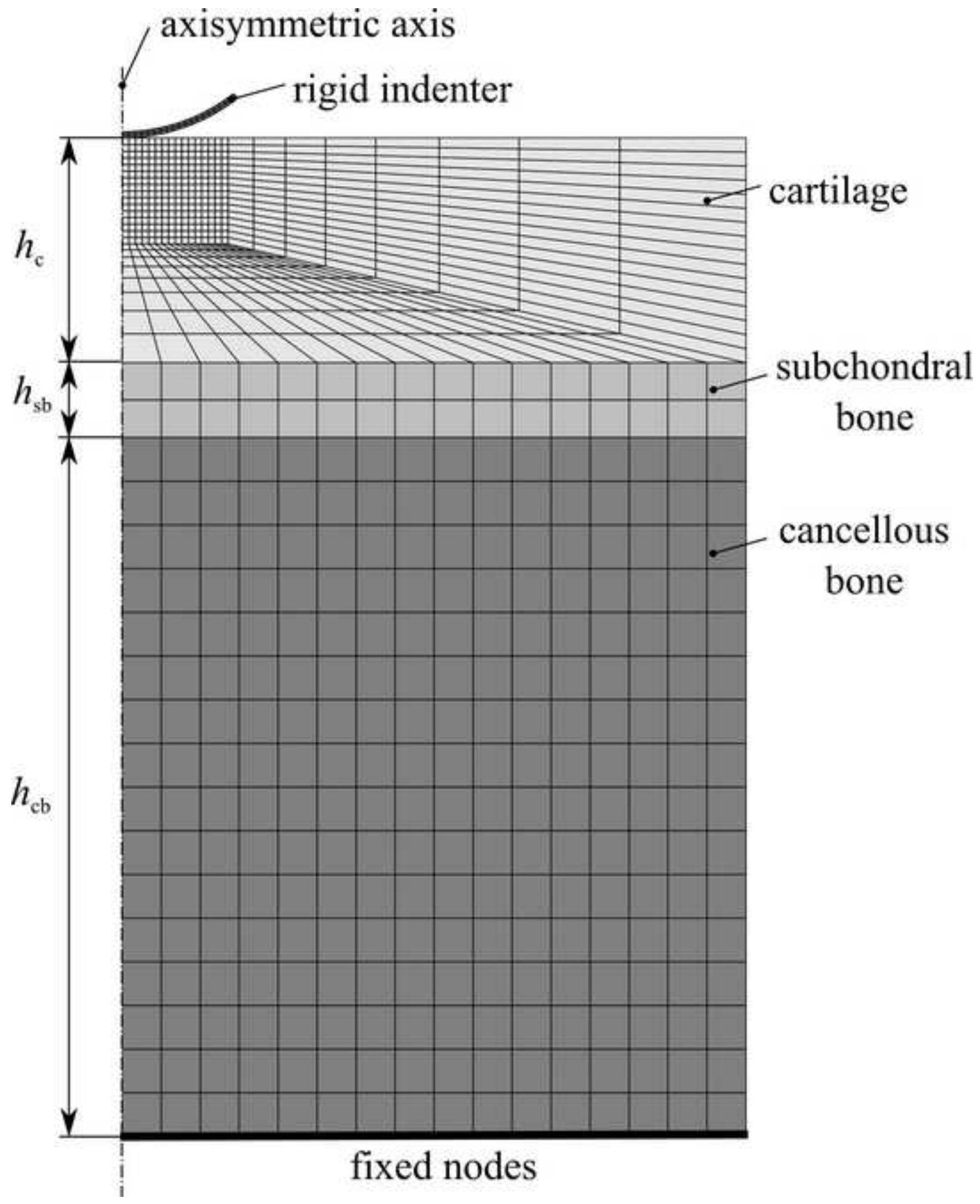


Click here to download high resolution image

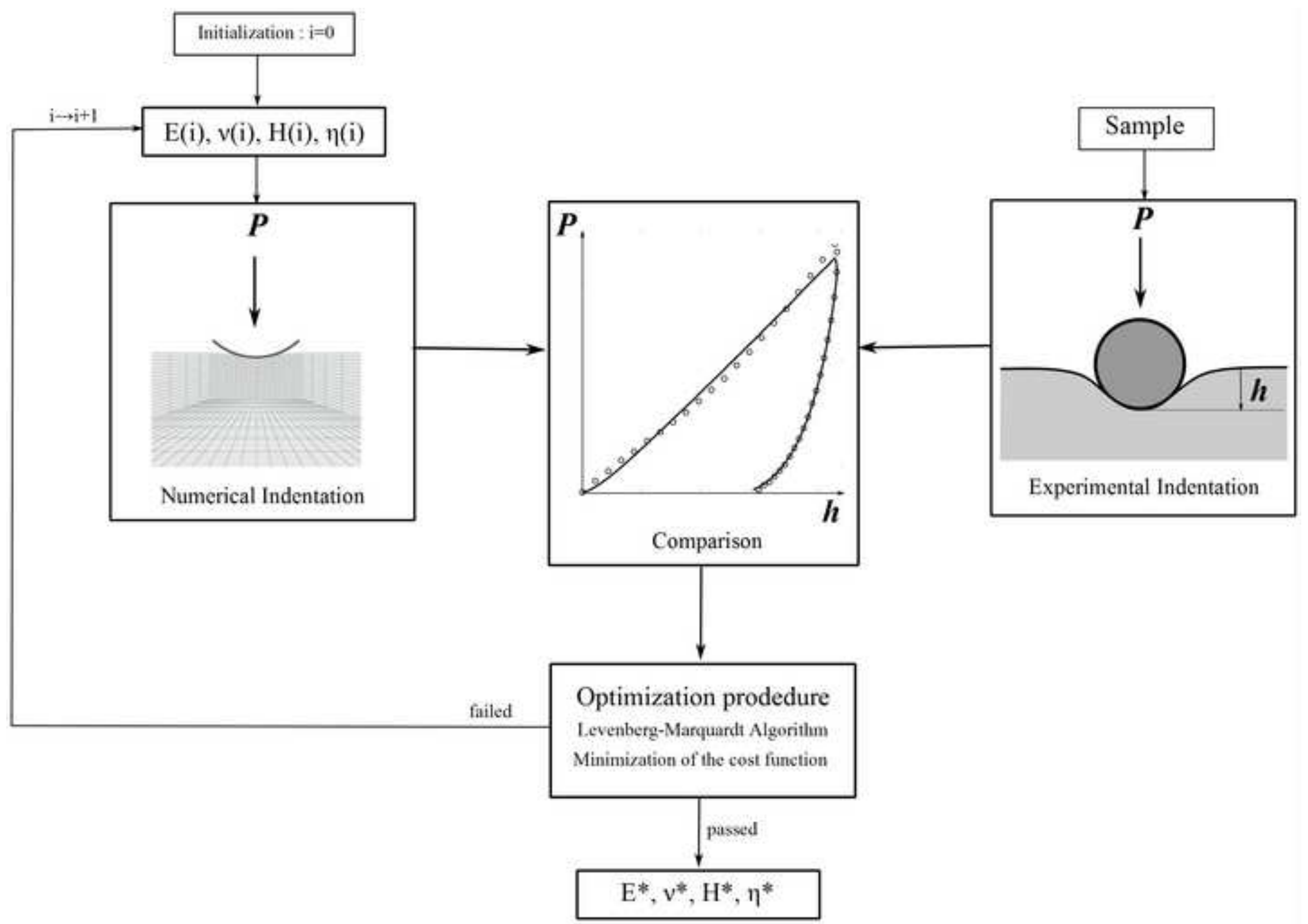




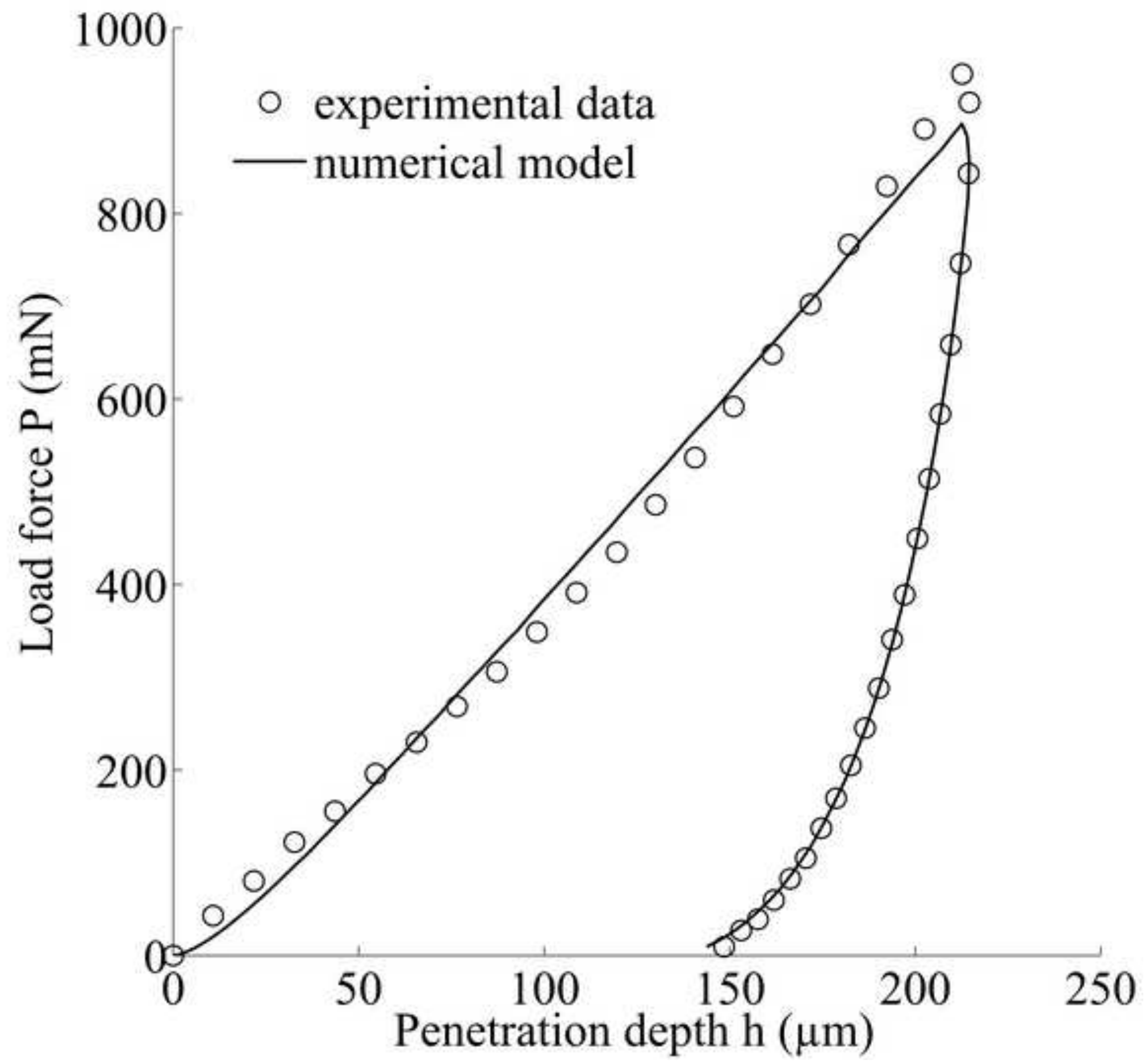


Figure7
Click here to download high resolution image

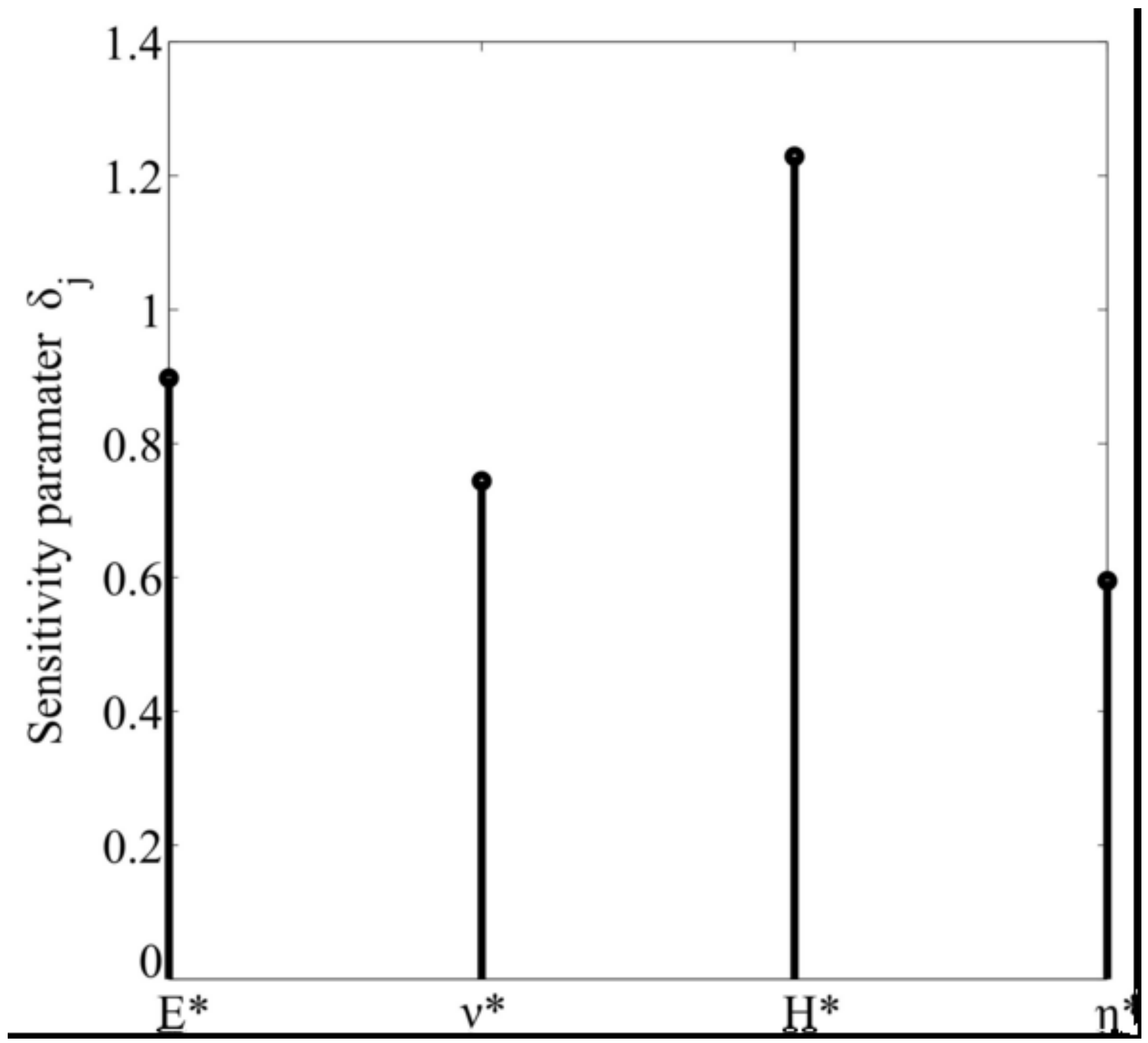



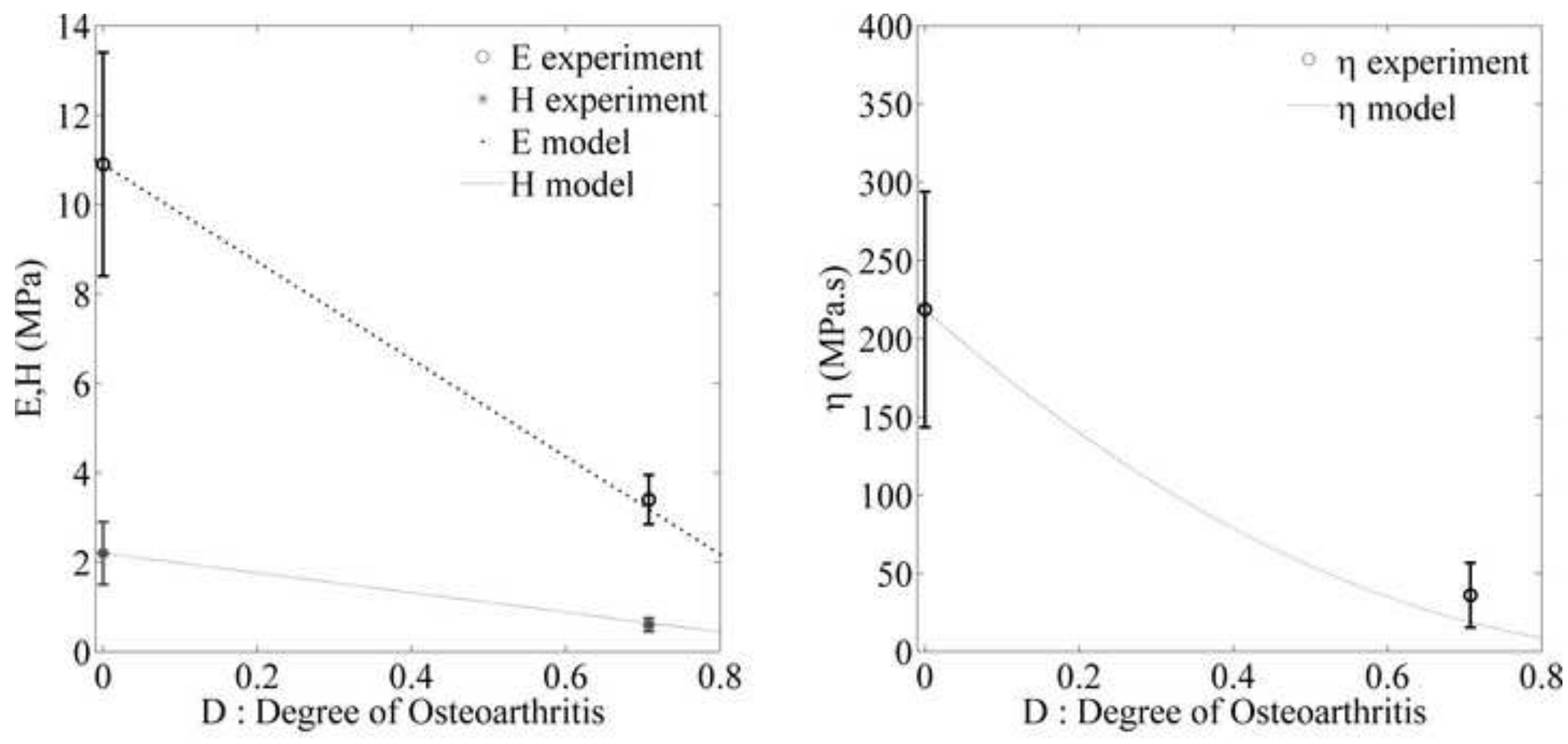
Table 1 - Some relevant characteristics of the normal subjects and patients with OA.

\begin{tabular}{|c|c|c|c|c|c|}
\hline Sujet & $\begin{array}{l}\text { Hip } \\
\text { replacement }\end{array}$ & Sex & $\begin{array}{l}\text { Height } \\
(\mathrm{mm})\end{array}$ & $\begin{array}{l}\text { Mass } \\
(\mathrm{kg})\end{array}$ & $\begin{array}{l}\text { Age } \\
\text { (years) }\end{array}$ \\
\hline \multicolumn{6}{|c|}{ Normal subjects } \\
\hline 1 & $\mathrm{P}$ & $\mathrm{F}$ & 165 & 63 & 81 \\
\hline 2 & $\mathrm{P}$ & $\mathrm{F}$ & 150 & 50 & 83 \\
\hline 3 & $\mathrm{P}$ & $\mathrm{F}$ & 168 & 65 & 73 \\
\hline 4 & $\mathrm{P}$ & $\mathrm{F}$ & 160 & 50 & 85 \\
\hline 5 & $\mathrm{P}$ & $\mathrm{F}$ & 160 & 60 & 94 \\
\hline 6 & $\mathrm{P}$ & $\mathrm{F}$ & 174 & 83 & 83 \\
\hline \multicolumn{6}{|c|}{ Patients with OA } \\
\hline 7 & $\mathrm{~T}$ & $\mathrm{M}$ & 172 & 85 & 77 \\
\hline 8 & $\mathrm{~T}$ & $\mathrm{~F}$ & 160 & 52 & 74 \\
\hline 9 & $\mathrm{~T}$ & $\mathrm{M}$ & 172 & 83 & 79 \\
\hline 10 & $\mathrm{~T}$ & $\mathrm{~F}$ & 160 & 89 & 57 \\
\hline
\end{tabular}

$\mathrm{M}=$ Male; $\mathrm{F}=$ Female $; \mathrm{P}=$ Partial $; \mathrm{T}=$ Total 
Table 2 - Identifiability measurement (<100 good; >1000 poor).

\begin{tabular}{|c|c|c|c|c|c|}
\hline$k$ & 4 & 3 & 3 & 3 & 3 \\
\hline parameter set & {$\left[E^{*}, v^{*}, H^{*}, \eta^{*}\right]$} & {$\left[v^{*}, H^{*}, \eta^{*}\right]$} & {$\left[E^{*}, H^{*}, \eta^{*}\right]$} & {$\left[E^{*}, v^{*}, \eta^{*}\right]$} & {$\left[E^{*}, v^{*}, H^{*}\right]$} \\
\hline$J_{E}$ & 330 & 223 & 70 & 30 & 95 \\
\hline
\end{tabular}


Table 3 - Viscoelastic parameters for normal cartilage. *(MPa), **MPa.s

\begin{tabular}{|c|c|c|c|c|c|c|c|c|c|c|c|c|c|c|c|c|}
\hline \multirow{2}{*}{$\begin{array}{l}\text { Area } \\
\text { Parameters }\end{array}$} & \multicolumn{4}{|c|}{ Superior } & \multicolumn{4}{|c|}{ Inferior } & \multicolumn{4}{|c|}{ Posterior } & \multicolumn{4}{|c|}{ Anterior } \\
\hline & $E *$ & $v$ & $H^{*}$ & $\eta * *$ & $E *$ & $v$ & $H^{*}$ & $\eta * *$ & $E^{*}$ & $v$ & $H^{*}$ & $\eta * *$ & $E^{*}$ & $v$ & $H^{*}$ & $\eta * *$ \\
\hline \multicolumn{17}{|l|}{ Femur 1} \\
\hline Mesure 1 & 11.57 & 0.40 & 3.24 & 12.23 & 13.31 & 0.49 & 0.15 & 367.29 & 9.67 & 0.49 & 0.35 & 531.12 & 10.22 & 0.48 & 0.86 & 353.11 \\
\hline Mesure 2 & 10.48 & 0.49 & 2.34 & 277.93 & 13.00 & 0.48 & 0.26 & 356.78 & 9.36 & 0.49 & 0.58 & 536.22 & 10.37 & 0.49 & 0.46 & 344.75 \\
\hline Mesure 3 & 9.56 & 0.49 & 2.28 & 270.73 & 13.31 & 0.48 & 0.15 & 367.29 & 9.96 & 0.48 & 0.45 & 323.58 & 9.92 & 0.49 & 0.14 & 430.38 \\
\hline \multicolumn{17}{|l|}{ Femur 2} \\
\hline Mesure 1 & 19.49 & 0.37 & 4.20 & 220.09 & 18.21 & 0.48 & 4.46 & 191.64 & 18.96 & 0.48 & 4.61 & 122.29 & 17.47 & 0.48 & 3.74 & 154.80 \\
\hline Mesure 2 & 16.68 & 0.48 & 3.50 & 214.77 & 16.48 & 0.48 & 4.16 & 184.55 & 19.50 & 0.49 & 4.00 & 214.89 & 19.18 & 0.48 & 4.01 & 220.96 \\
\hline Mesure 3 & 17.57 & 0.37 & 3.90 & 262.40 & 20.25 & 0.48 & 4.45 & 319.05 & 18.48 & 0.48 & 4.34 & 217.93 & 19.87 & 0.48 & 4.12 & 198.79 \\
\hline \multicolumn{17}{|l|}{ Femur 3} \\
\hline Mesure 1 & 8.35 & 0.41 & 3.05 & 110.04 & 11.34 & 0.48 & 2.79 & 113.02 & 8.66 & 0.48 & 2.64 & 131.80 & 12.72 & 0.40 & 2.31 & 83.30 \\
\hline Mesure 2 & 8.28 & 0.43 & 3.11 & 128.57 & 12.53 & 0.48 & 2.91 & 128.69 & 8.41 & 0.48 & 2.47 & 128.15 & 10.46 & 0.48 & 2.54 & 94.10 \\
\hline Mesure 3 & & & & & 11.84 & 0.48 & 2.83 & 127.24 & 12.87 & 0.48 & 2.80 & 139.09 & 12.41 & 0.49 & 2.85 & 108.37 \\
\hline \multicolumn{17}{|l|}{ Femur 4} \\
\hline Mesure 1 & 3.33 & 0.49 & 1.38 & 29.37 & 3.48 & 0.49 & 1.42 & 30.98 & 4.12 & 0.40 & 1.52 & 34.63 & 5.17 & 0.49 & 1.67 & 136.91 \\
\hline Mesure 2 & 2.91 & 0.45 & 1.19 & 31.79 & 14.12 & 0.48 & 0.34 & 304.38 & 3.75 & 0.49 & 1.49 & 36.45 & 4.73 & 0.48 & 1.62 & 98.42 \\
\hline Mesure 3 & 3.10 & 0.45 & 1.15 & 28.82 & 5.39 & 0.49 & 0.09 & 199.82 & 3.51 & 0.46 & 1.21 & 29.75 & 4.78 & 0.43 & 0.30 & 173.35 \\
\hline \multicolumn{17}{|l|}{ Femur 5} \\
\hline Mesure 1 & 10.30 & 0.48 & 0.08 & 499.21 & 3.44 & 0.48 & 0.85 & 26.29 & 12.12 & 0.48 & 2.39 & 344.33 & 14.12 & 0.48 & 5.78 & 366.09 \\
\hline Mesure 2 & 7.79 & 0.47 & 0.08 & 456.44 & 2.03 & 0.48 & 0.49 & 11.81 & 10.94 & 0.48 & 3.01 & 284.87 & 16.48 & 0.46 & 0.14 & 810.59 \\
\hline Mesure 3 & 7.74 & 0.48 & 0.24 & 462.65 & 2.97 & 0.48 & 0.72 & 18.47 & 10.22 & 0.48 & 2.55 & 206.74 & 14.05 & 0.46 & 1.74 & 595.20 \\
\hline \multicolumn{17}{|l|}{ Femur 6} \\
\hline Mesure 1 & 15.54 & 0.40 & 4.09 & 234.79 & 6.57 & 0.48 & 2.00 & 65.90 & 10.33 & 0.49 & 3.34 & 208.68 & 9.72 & 0.45 & 3.03 & 136.88 \\
\hline Mesure 2 & 17.67 & 0.46 & 5.46 & 238.03 & 5.67 & 0.49 & 1.47 & 51.22 & 10.59 & 0.47 & 0.21 & 396.46 & 9.72 & 0.46 & 3.43 & 140.86 \\
\hline Mesure 3 & 18.45 & 0.48 & 6.01 & 312.33 & 7.30 & 0.49 & 1.95 & 62.43 & 10.64 & 0.48 & 0.72 & 407.46 & 10.75 & 0.47 & 0.37 & 165.38 \\
\hline
\end{tabular}


Table 4 - Viscoelastic parameters for OA cartilage. *(MPa), **MPa.s

\begin{tabular}{|c|c|c|c|c|c|c|c|c|c|c|c|c|c|c|c|c|}
\hline \multirow{2}{*}{$\frac{\text { Area }}{\text { Parameters }}$} & \multicolumn{4}{|c|}{ Superior } & \multicolumn{4}{|c|}{ Inferior } & \multicolumn{4}{|c|}{ Posterior } & \multicolumn{4}{|c|}{ Anterior } \\
\hline & $E^{*}$ & $v$ & $H^{*}$ & $\eta * *$ & $E^{*}$ & $v$ & $H *$ & $\eta * *$ & $E *$ & $v$ & $H *$ & $\eta * *$ & $E *$ & $v$ & $H^{*}$ & $\eta * *$ \\
\hline \multicolumn{17}{|l|}{ Femur 7} \\
\hline Mesure 1 & & & & & 2.23 & 0.49 & 0.81 & 16.52 & 3.95 & 0.40 & 0.90 & 20.33 & & & & \\
\hline Mesure 2 & & & & & 5.95 & 0.49 & 0.85 & 13.26 & 3.84 & 0.49 & 0.94 & 23.50 & & & & \\
\hline Mesure 3 & & & & & & & & & 3.54 & 0.49 & 0.93 & 22.35 & & & & \\
\hline \multicolumn{17}{|l|}{ Femur 8} \\
\hline Mesure 1 & & & & & & & & & 5.23 & 0.45 & 1.02 & 97.78 & & & & \\
\hline Mesure 2 & & & & & & & & & 3.89 & 0.45 & 0.21 & 82.49 & & & & \\
\hline Mesure 3 & & & & & & & & & 4.87 & 0.45 & 0.00 & 149.17 & & & & \\
\hline \multicolumn{17}{|l|}{ Femur 9} \\
\hline Mesure 1 & & & & & 1.98 & 0.49 & 0.29 & 13.26 & & & & & & & & \\
\hline Mesure 2 & & & & & 2.17 & 0.49 & 0.32 & 14.19 & & & & & & & & \\
\hline Mesure 3 & & & & & 2.43 & 0.49 & 0.29 & 13.62 & & & & & & & & \\
\hline \multicolumn{17}{|l|}{ Femur 10} \\
\hline Mesure 1 & & & & & & & & & & & & & 2.61 & 0.45 & 0.49 & 18.85 \\
\hline Mesure 2 & & & & & & & & & & & & & 2.15 & 0.45 & 0.79 & 20.17 \\
\hline Mesure 3 & & & & & & & & & & & & & & & & \\
\hline
\end{tabular}


Table 5 - Distribution of parameters $E, v, H$ and $\eta$ for normal and OA cartilage (n: number of samples, NC: Non Calculable, SD: Standard Deviation).

\begin{tabular}{|c|c|c|c|c|c|c|c|}
\hline \multirow[t]{2}{*}{ Parameter } & \multirow[t]{2}{*}{ Position } & \multicolumn{3}{|l|}{ Normal } & \multicolumn{3}{|l|}{$\mathbf{O A}$} \\
\hline & & $\mathrm{n}$ & Mean & $\mathrm{SD}^{*}$ & $\mathrm{n}$ & Mean & $\mathrm{SD}^{*}$ \\
\hline \multirow[t]{5}{*}{$E(\mathrm{MPa})$} & Global & 24 & 10.9 & 5.0 & 5 & 3.4 & 1.1 \\
\hline & Superior & 6 & 11.1 & 5.5 & 0 & $\mathrm{NC}$ & $\mathrm{NC}$ \\
\hline & Inferior & 6 & 10.1 & 5.6 & 2 & 3.1 & 1.3 \\
\hline & Posterior & 6 & 10.7 & 4.9 & 2 & 4.2 & 0.6 \\
\hline & Anterior & 6 & 11.8 & 4.7 & 1 & 2.4 & $\mathrm{NC}$ \\
\hline \multirow[t]{5}{*}{$v$} & Global & 24 & 0.47 & 0.02 & 5 & 0.47 & 0.02 \\
\hline & Superior & 6 & 0.45 & 0.03 & 0 & $\mathrm{NC}$ & $\mathrm{NC}$ \\
\hline & Inferior & 6 & 0.48 & 0.00 & 2 & 0.49 & 0.00 \\
\hline & Posterior & 6 & 0.48 & 0.01 & 2 & 0.46 & 0.01 \\
\hline & Anterior & 6 & 0.47 & 0.01 & 1 & 0.45 & $\mathrm{NC}$ \\
\hline \multirow[t]{5}{*}{$H(\mathrm{MPa})$} & Global & 24 & 2.2 & 1.4 & 5 & 0.6 & 0.3 \\
\hline & Superior & 6 & 2.7 & 1.7 & 0 & $\mathrm{NC}$ & $\mathrm{NC}$ \\
\hline & Inferior & 6 & 1.8 & 1.7 & 2 & 0.6 & 0.4 \\
\hline & Posterior & 6 & 2.2 & 1.5 & 2 & 0.7 & 0.4 \\
\hline & Anterior & 6 & 2.2 & 1.2 & 1 & 0.6 & $\mathrm{NC}$ \\
\hline \multirow[t]{5}{*}{$\eta$ (MPa.s) } & Global & 24 & 218.7 & 150.6 & 5 & 36.0 & 41.4 \\
\hline & Superior & 6 & 217.9 & 150.4 & 0 & $\mathrm{NC}$ & $\mathrm{NC}$ \\
\hline & Inferior & 6 & 162.6 & 125.4 & 2 & 14.3 & 0.8 \\
\hline & Posterior & 6 & 238.6 & 153.9 & 2 & 65.9 & 62.0 \\
\hline & Anterior & 6 & 256.2 & 191.5 & 1 & 19.5 & $\mathrm{NC}$ \\
\hline
\end{tabular}


Table 6 - Thermodynamic variables.

\begin{tabular}{lll}
\hline State variables & \multicolumn{2}{c}{ Associated variables } \\
\cline { 1 - 2 } Observable & Internal & \\
\hline$\varepsilon$ & & $\boldsymbol{\sigma}$ \\
$\boldsymbol{\varepsilon}^{e}$ & $\boldsymbol{\sigma}$ \\
$\boldsymbol{\varepsilon}^{v}$ & $-\boldsymbol{\sigma}$ \\
$\boldsymbol{\alpha}$ & $\mathbf{X}$ \\
$D$ & $Y$ \\
\hline
\end{tabular}

